\title{
ATIVIDADES PARA O ENSINO DE ONDAS SONORAS AOS ALUNOS SURDOS: UMA PROPOSTA INCLUSIVA \\ ACTIVITIES FOR THE EDUCATION OF SOUND WAVES TO DEAF STUDENTS: AN INCLUSIVE PROPOSAL
}

\author{
Eduardo Bruno Da Rocha Sampaio - UFF \\ Isa Costa - Instituto de Física - UFF \\ Ruth Maria Mariani Braz - CMPDI - UFF ${ }^{1}$
}

\begin{abstract}
Resumo
O projeto "Atividades para o Ensino de Ondas Sonoras" é uma proposta inclusiva que tem como objetivo possibilitar que os alunos surdos e ouvintes tenham as mesmas condições de assimilar o referido conteúdo, incluso no Currículo Mínimo de Física para o Ensino Médio. A metodologia utilizada foi o simulador PhET. Foram explorados os sentidos de tato e visão dos surdos. Esteve ainda disponível na sala de aula o apoio de uma intérprete da língua brasileira de sinais. Foi neste contexto que os alunos puderam aprender através da exploração e da descoberta. A proposta foi aplicada com êxito entre alunos de uma escola pública, inseridos em diferentes séries dos Ensinos Fundamental e Médio. Tivemos como resultado o sucesso dos alunos surdos nesta aprendizagem, bem como o neologismo de dois sinais em Libras: um para ultrassom e o outro para infrassom.
\end{abstract}

Palavras chave: Ensino de física. Materiais didáticos. Glossário de Libras.

\begin{abstract}
The project "Activities for the teaching of Sound Waves" is an inclusive proposal that aims to allow that both deaf and hearing students could learn the above content, part of the Physics Minimum Curriculum for the High school. The methodology applied was the PhET simulator. Deaf student's tact and vision were explored. It was also available in the classroom the support of a Brazilian signal language interpreter. It was in this educational context that the students were able to learn trough research and discovery. The approach was successfully applied in a public high school, with students from different grades. Deaf students successfully learned the content, and also created two new signals: one for ultrasound and another for infrasound.
\end{abstract}

Keywords: Physics teaching, Teaching materials. Libras glossary.

\footnotetext{
${ }^{1}$ Doutora em Ciências e Biotecnologia, do Instituto de Biologia da Universidade Federal Fluminense. Professor docente I - Secretária de Educação do Estado do Rio de Janeiro e professor colaborador do Curso de mestrado profissional em Diversidade e Inclusão da UFF. Coordenadora executiva do projeto Internacional Spreed The Sign no Brasil. Orientadora de alunos do curso de Mestrado Profissional de Diversidade e Inclusão do Instituto de Biologia da UFF. Email: ruthmariani@yahoo.com.br.
} 


\section{INTRODUÇÃO}

A escola tem um papel essencial no processo de desenvolvimento da aprendizagem e valorização de todos, como preve a Constituição Federal de 1988, no Art. 3으, inciso IV, (BRASIL, 1988). E a Universidade vem buscando propostas que auxiliem na formação do professor, inicial ou continuada, que estejam em conformidade com os aspectos sociais, políticos e culturais da realidade atual, procurando minimizar desigualdades e oferecer reais oportunidades de inserção no mercado de trabalho.

A nossa responsabilidade como educadores, em qualquer nível de escolaridade, tem sido a de promover o acesso aos conhecimentos cotidianos e científicos aos quais, muitas vezes, as pessoas com deficiência auditiva ou surdas estão à margem, pois no ambiente familiar a maioria dos pais são ouvintes $95 \%$ e desconhecem a Língua Brasileira de Sinais (Libras), (MARIANI, 2014). A aquisição dos conhecimentos escolares acontece de uma forma gradativa, pois é evidente também a necessidade que o surdo tem de estar em contato precoce e permanente com os membros da comunidade para compartilhar das experiências linguísticas, fundamentais a um desenvolvimento global, no qual ele possa competir no mercado de trabalho. Para tentar diminuir esse impasse, surgiu uma proposta do Ministério da Educação (MEC), por meio da Secretaria de Educação Continuada,Alfabetização, Diversidade e Inclusão ( SECADI):

Para o ingresso dos alunos surdos nas escolas comuns, a educação bilíngue - Língua Portuguesa/ Libras desenvolve o ensino escolar na Língua Portuguesa e na língua de sinais, o ensino da Língua Portuguesa como segunda língua na modalidade escrita para alunos surdos, os serviços de tradutor/intérprete de Libras e Língua Portuguesa e o ensino da Libras para os demais alunos da escola. $O$ atendimento educacional especializado para esses alunos é ofertado tanto na modalidade oral e escrita quanto na língua de sinais. Devido à diferença linguística, orienta-se que o aluno surdo esteja com outros surdos em turmas comuns na escola regular (BRASIL, 2008, p. 16).

Cada deficiência requer: estratégias e materiais específicos e diversificados, recursos tecnológicos, equipamentos e jogos pedagógicos que contribuem para que 
situações de aprendizagens sejam mais agradáveis e motivadoras em um ambiente de cooperação e reconhecimento das diferenças. Com bom senso e criatividade, é possível selecionar, confeccionar ou adaptar recursos abrangentes ou de uso específico.

Muitos dos deficientes auditivos e os surdos frequentam o Atendimento educacional especializado ( $A E E$ ) em salas de recursos Multifuncionais (SRM) que são um conjunto de procedimentos definidos em uma proposta pedagógica, assegurando um conjunto de recursos e serviços educacionais especiais, organizados institucionalmente para apoiar, complementar, suplementar, de modo a garantir a educação escolar e promover o desenvolvimento das potencialidades dos educandos que apresentem deficiências, em todos os níveis, etapas e modalidades da educação.

O AEE para o surdo ou o deficiente auditivo é realizado mediante a atuação de profissionais com conhecimentos específicos no ensino da Libras, da Língua Portuguesa na modalidade escrita como segunda língua, da adequação e produção de materiais didáticos e pedagógicos, da tecnologia assistiva e outros.

Alguns autores como Marinho (2007), Runjanenek (2011) e Mariani (2014) identificaram que há carência de sinais com relação a determinados temas e também descreveram o despreparo dos intérpretes, que muitas vezes não possuem nível superior, apenas o técnico e assim passam as informações do professor de forma equivocada, pelo fato de não estarem familiarizados com elas. Despreparo tanto por apatia dos intérpretes quanto dos professores, que são os detentores do conhecimento, tendo em vista que os intérpretes não têm a obrigação de saber a fundo os conceitos abordados em todas as disciplinas curriculares.

O mais apropriado seria um trabalho em conjunto, professores/intérpretes. Esses deveriam preparar o roteiro da aula juntos, para adaptar determinados termos que poderiam ter um duplo sentido na língua natal dos surdos, por deficiência dela, ou seja, palavras que não possuem sinais, ou por outros fatores.

Existem casos, relacionados ao vocabulário da Libras de palavras que caíram no esquecimento, caso observado na aplicação deste projeto, e, em casos extremos, 
alunos que não tiveram incentivos da família para que fossem incluídos em outros grupos, e não conheciam certos termos, caso observado pelos autores Plaça et al (s/d).

Passou-se a pensar no conceito de diversidade. Este trata que todos os alunos têm alguma necessidade acadêmica independente de possuir, ou não, alguma deficiência. O ensino especial, a inclusão, deve ser para todos, não só para alunos com deficiência.

Para que seja possível haver inclusão nas salas de aula, podem e devem ser feitas adaptações curriculares viabilizando a aprendizagem dos alunos, quando necessário. Como propõem os Parâmetros Curriculares Nacionais (PCN) - Adaptações Curriculares (1998):

As adaptações curriculares constituem, pois, possibilidades educacionais de atuar frente às dificuldades de aprendizagem dos alunos. Pressupõem que se realize a adaptação do currículo regular, quando necessário, para torná-lo apropriado às peculiaridades dos alunos com necessidades especiais. Não um novo currículo, mas um currículo dinâmico, alterável, passível de ampliação, para que atenda realmente a todos educandos (BRASIL, 1998, p. 34).

Estas adaptações no currículo ou nas metodologias de ensino para que possibilitem aos surdos o exercício da cooperatividade, da comunicação, o desejo de polir e aprimorar a afetividade têm levado os alunos a uma autonomia significativa, oportunizando o desenvolvimento pessoal/social do grupo e o engajamento na transformação da comunidade escolar. Muitas vezes esses alunos ouvintes que aprenderam a Libras, auxiliam os alunos surdos na confecção, ou no caso de uma apresentação de trabalhos ou na interpretação de provas.

Outras dificuldades apontadas pelos professores, intérpretes e até mesmo os alunos surdos são relacionadas aos livros didáticos. Neste trabalho focalizamos o tema da disciplina de Física, Ondas Sonoras; o conceito trabalhado é baseado em exemplos cotidianos, com relação a ouvintes, porém totalmente abstratos com relação aos surdos. Até mesmo as imagens ilustram situações em que um aluno surdo não vivenciou. 
Esses recursos metodológicos são efetivos para alunos ouvintes, mas praticamente impossibilitam os alunos surdos a compreenderem o fenômeno. Os livros didáticos devem propor exemplos, além dos que já propõem, de situações em que um aluno surdo possa compreender, ou seja, exemplos em que não haja a necessidade de ouvir para compreender.

Porém, os alunos considerados normais também possuem dificuldades que, muitas vezes, não são superadas. Esse fato leva ao seguinte questionamento: quais as estratégias que poderemos usar para o ensino de ondas sonoras com turmas de alunos com ou sem deficiências auditivas ou surdos, incluídos no ensino regular?

O ponto de partida para explicar o que são ondas sonoras para alunos surdos é o fato de que ondas sonoras são ondas mecânicas, logo, necessitam de um meio para se propagar. E, de fato, elas se propagam no ar através da variação de pressão deste, até chegar aos nossos ouvidos, e assim, nós, ouvintes, escutamos. Mas as ondas sonoras não se propagam somente no ar. Elas também se propagam na água, por exemplo. Isso possibilita a utilização de uma ferramenta marítima chamada sonar, existente em embarcações e submarinos, para detectar objetos ao seu redor. Mas golfinhos e morcegos usam também ondas sonoras para se comunicar, e até se localizar.

Uma situação cotidiana que contribui para o desenrolar desse tema é a aproximação de caixas de som ligadas, pois, tanto os surdos quanto os ouvintes conseguem sentir as ondas sonoras quando se aproximam de uma caixa de som através do tato. Principalmente os sons mais graves.

O que diferencia o ensino de ondas sonoras para alunos ouvintes daquele para turmas com alunos surdos também é a exploração dessa característica das ondas sonoras: a percepção das vibrações em meios materiais.

\subsection{Os livros didáticos e a escolha do tema para a proposta de ensino.}

Nogueira; et.al.; (2005) apontam uma dificuldade relacionada à comunicação com esse indivíduo, pois a linguagem, tanto oral quanto escrita, de um ouvinte (no 
caso, Língua Portuguesa) é diferente da Libras, principalmente para os que nasceram surdos, pois não chegaram a ter contato com a linguagem oral. Muitos pensam que o aluno surdo tem capacidade intelectual afetada, mas não passa de uma dificuldade de comunicação com o educador e com os colegas de classe. Como citado por Nogueira et.al.; (2005):

a falta de audição não afeta as capacidades intelectuais, mas limita a possibilidade de aquisição de conhecimentos transmitidos oralmente, prejudicando o desenvolvimento do raciocínio abstrato, já que haverá dificuldades em formar conceitos simbólicos, que não necessitem da exploração concreta dos objetos, (NOGUEIRA, et.al.; 2005,p.1).

Os conceitos a serem aprendidos devem partir de situações que os alunos já vivenciaram de alguma maneira, como cita Carvalho (1992):

A descoberta de que os alunos trazem para as salas de aula conceitos estruturados, com toda uma lógica própria e coerente e um desenvolvimento causal que é fruto de seus intentos para dar sentido às atividades cotidianas, mas, diferente da estrutura e da lógica usadas na definição científica desse conceito, abalou o ensino, que tinha como pressuposto que o aluno era uma tabula rasa, ou seja, ele não sabia nada sobre o que pretendíamos ensinar, (CARVALHO, 1992, p. 48).

A aprendizagem deve partir dos conceitos prévios dos alunos. Os livros didáticos devem utilizar exemplos abrangentes ao cotidiano do máximo de públicos distintos possíveis. Porém, nesse tema, não inclui as vivências do público surdo.

Logo, para a política de inclusão de alunos com deficiências funcionar, deve haver uma preocupação com relação a determinados tópicos, principalmente os relacionados ao ensino de Ciências, que além de contarem com palavras científicas, muitas vezes não estão presentes na língua do indivíduo. Existem também impasses, como o caso do estudo de ondas sonoras para os alunos surdos e o estudo de óptica para os alunos cegos, entre outros. Se nós, professores, pararmos para pensar nesses alunos com deficiências, a proposta de ensino mais viável para eles terem uma aprendizagem significativa é aquela que aproveita os sentidos que eles têm mais aguçados. 
Outro texto importante para a escolha do tema foi o de Nascimento Neto (2012). O autor, junto a um grupo de pesquisa, iniciou um projeto de análise de livros didáticos a fim de evidenciar formas de abordagem do tema: acústica. Porém, percebeu que as explicações dos livros didáticos, relacionadas a esse tema, se baseavam em situações práticas, que envolviam contextos para pessoas ouvintes, ou seja, os quais um aluno com deficiência auditiva, em geral, não vivenciou. Fato semelhante ao encontrado pelos autores do texto anterior. $\mathrm{O}$ que para pessoas consideradas "normais", ou ouvintes, são exemplos simples, claros e efetivos, para os alunos com deficiência auditiva são exemplos complexos e praticamente, ou totalmente, inúteis, que culminam na impossibilidade do aprendizado, ou seja, a inclusão desse grupo de alunos.

Muitos educadores acreditam que alunos com deficiência, em geral têm "dificuldade de aprender". Porém, qualquer aluno terá dificuldades quando não se dá as condições adequadas para que seja possível aprender. Como a situação dos livros didáticos, que baseiam suas explicações em situações práticas para um ouvinte, mas que para um aluno surdo são inacessíveis. Além dessa, existem dificuldades mais comuns, que são o caso da comunicação. Como citado anteriormente, referindo-se a textos de outros autores, os surdos se comunicam em Libras, que é muito diferente da Língua Portuguesa, que é a língua, geralmente, utilizada pelos professores para ministrar as aulas. Como cita Nascimento Neto (2012) a respeito do que consta na LDB:

A Lei de Diretrizes e Bases da Educação (LDB) no 9.493/96 estabelece em seu artigo $59^{\circ}$, parágrafo III, que estarão assegurados aos alunos com necessidades especiais, professores com especialização adequada em nível médio ou superior para atendimento especializado, bem como professores do ensino regular capacitados para a integração desses educandos nas classes comuns. Também é importante ressaltar que, nas escolas que atendem alunos surdos, as aulas devem ser ministradas com um enfoque bilíngue, [...] (BRASIL, 1996, p.1).

Pesquisas relacionadas ao material didático utilizado pelos professores em suas turmas chegam à conclusão que, a maioria só se baseia no livro didático. Se isso for feito em uma turma onde se encontram alunos surdos, praticamente impossibilita a 
compreensão desse tema que, diga-se de passagem, está incluso no Currículo Mínimo de Física (ESTADO DO RIO DE JANEIRO, 2012), logo se subentende que é importante para a formação de um cidadão, que é o seu objetivo principal, e é cobrado em concursos para ingresso em universidades públicas. Fatores que impossibilitam e contradizem a ideia de inclusão. Assim, este artigo tem como objetivo relatar uma experiência exitosa no ensino de ondas sonoras com alunos surdos incluídos no ensino regular.

\section{METODOLOGIA}

A ideia do projeto Atividades para o ensino de Ondas Sonoras: uma proposta inclusiva surgiu com o intuito de tentar minimizar as dificuldades impostas pela formação de professores, que deixa a desejar quando se trata da prática de educação inclusiva e pelos próprios livros didáticos, que baseiam suas explicações, com relação ao tema escolhido, em situações-problema que não se aplicam ao cotidiano dos alunos surdos.

Optamos pela metodologia do estudo de caso, o que exigiu um empenho dos discentes para reconhecer o problema, desenvolver estratégias, calcular e propor soluções onde previu-se três passos: planejamento, implementação e avaliação de uma mudança para melhora de sua prática quanto da própria investigação (TRIPP, 2005, p. 2). Aplicamos o projeto PhET, que são demonstrações Interativas, criado por Carl Wieman, Boulder (2002) que envolvem os alunos através de um ambiente intuitivo, estilo jogo, onde os alunos conhecem através da exploração e da descoberta. Dividimos o tema em aulas com os seguintes tópicos

O que são ondas?
1. Problematização
2. Perguntas-chave
3. Conceitos-chave
4. Classificações das ondas 
5. Elementos de uma onda

6. A equação fundamental das ondas

7. Ondas sonoras

8. Formação das ondas sonoras

9. Frequência e velocidade das ondas sonoras

10. Transmissão do som

11. Intensidade, timbre e altura

12. Instrumentos musicais

13. Efeitos sonoros

14. Aplicações do eco

15. Atividades experimentais

16. Avaliação da aprendizagem

\section{Resultados:}

Para facilitar a compreensão de alguns conceitos físicos foram utilizados alguns recursos, como: imagens, vídeos, caixa de som e simulações de computador. As atividades na SRM da escola estadual do RJ (Instituto de Educação Ismael Coutinho) foram realizadas em quatro encontros com alunos surdos e as intervenções conjuntas de uma intérprete de LIBRAS e da professora que coordena a Sala e fez registros gravados em vídeo e áudio. Cada encontro será relatado em seguida.

\section{$1^{\circ}$ encontro (Tempo aproximado: 01:00 $\mathrm{h}$; participantes: 13 )}

Todos os encontros foram realizados na SRM. Iniciamos com a seguinte pergunta: "O que são ondas?". A partir dessa pergunta surgiram algumas situações que os alunos já haviam presenciado, e uma delas foi a onda no mar. A partir disso, foi discutido que esse era um tipo de onda, mas o conceito de onda de uma forma geral é: a partir de perturbações em um determinado meio, nesse caso a água, são geradas ondas. Foram projetados vídeos ${ }^{2}$, de poucos segundos, com situações em que ocorrem

\footnotetext{
${ }^{4}$ http://www.youtube.com/watch?v=14HYrtMI7U\&hd=1 http://www.youtube.com/watch?v=RmeZnW8Nc_A http://www.youtube.com/watch?v=y2yFHhfOVJM\&hd=1
} 
perturbações em um determinado meio, e, assim, foram geradas ondas. Esses vídeos exibiam: ondas no mar, um prédio balançando devido a um terremoto e uma "ola" feita pela torcida do Brasil em um jogo da Seleção Brasileira. Usando esses exemplos, foi comentado que as ondas não transportam matéria, mas sim energia. No caso do exemplo das ondas no mar, foi feita uma analogia a um barco no mar, com o motor desligado, em um dia de pequenas ondulações marítimas e de pouco vento. Pode-se perceber que o barco só sobe e desce. Isso acontece porque uma onda não transporta matéria. Logo, a energia que está se propagando na água apenas faz com que ela oscile na transversal à direção de propagação da onda.

Outra analogia foi feita através do vídeo com a "ola" da torcida do Brasil, onde é perceptível a propagação da onda, sem a necessidade das pessoas que compõem a "ola" mudarem de lugar, "sem andar com a onda".

O último exemplo utilizado foi através de uma simulação do $\mathrm{PhET}^{3}$ (Physics Education Technology) de ondas em uma corda. Nela, a corda é representada por vários pontos consecutivos, e quando ocorre uma perturbação nesta, uma onda se propaga na corda, mas os pontos só sobem e descem; eles não se deslocam junto à onda.

Depois de discutir a definição e dar exemplos de situações em que ocorre a propagação de uma onda, foi falado que essas podem ser classificadas quanto à: direção de propagação, natureza e direção de vibração.

Na classificação quanto à direção de propagação foram usados, inicialmente, vídeos para ilustrar o significado de movimentos unidimensionais, bidimensionais e tridimensionais. No movimento unidimensional foi projetado o vídeo ${ }^{4}$ de uma mola recebendo alguns pulsos, onde se percebe que as partes que ficam comprimidas devido a estes, aparentemente "se deslocam" em cima da mola, ou seja, em uma direção.

No movimento bidimensional foi exibido o vídeo ${ }^{5}$ da cena do videogame Super Nintendo, chamado Super Mário World, em que o Mário, que era o personagem

\footnotetext{
${ }^{3}$ http://phet.colorado.edu

${ }^{4}$ http://www.youtube.com/watch?v=04ECg1glu2s\&hd=1

5 http://www.youtube.com/watch?v=TfVy7wbwEyE\&hd=1
} 
controlado pelo jogador, só podia se mover na horizontal e na vertical (jogo 2D), ou seja, em duas direções ou dimensões.

No movimento tridimensional foi mostrado o vídeo ${ }^{6}$ da cena do videogame chamado Tony Hawk, em que o personagem controlado pelo jogador anda de skate em todas as direções possíveis, horizontal, vertical e para dentro, e para fora, da tela (jogo 3D), ou seja, em três direções ou dimensões.

Depois de trabalhados esses termos (movimentos unidimensionais, bidimensionais e tridimensionais) foram projetados vídeos de propagação de ondas unidimensionais, bidimensionais e tridimensionais. Para representar as ondas unidimensionais, o vídeo ${ }^{7}$ utilizado foi o mesmo utilizado para mostrar o que era um movimento unidimensional. Mas o que representou o movimento bidimensional foi um vídeo ${ }^{8}$ de um recipiente com água, inicialmente parada, e em sequência começam a cair gotas de água dentro dele. É perceptível que essas gotas causam uma perturbação na água, que estava inicialmente parada. Formam-se ondas circulares na superfície da água. Dizer que essas ondas propagam-se em uma superfície é o mesmo que dizer que elas se propagam, somente, em duas direções, ou seja, são ondas bidimensionais.

Para representar as ondas tridimensionais, o vídeo ${ }^{9}$ utilizado foi o de uma lâmpada acendendo em uma sala, e aumentando sua intensidade em intervalos de tempo perceptíveis. Nesse vídeo é perceptível que a luz, que é um tipo de onda, alcança todos os pontos da sala, ou seja, propaga-se em todas as direções. Dizer que uma onda se propaga em todas as direções é o mesmo que dizer que ela se propaga em três direções, ou seja, ela é uma onda tridimensional.

$\mathrm{Na}$ classificação quanto à natureza foi discutido que uma onda poderia ser classificada como: mecânica e eletromagnética. Nesse caso, apenas foram utilizadas as definições e exemplos. No caso das ondas mecânicas, que, por definição, necessitam de um meio material para se propagar, os exemplos utilizados foram: ondas se propagando através de uma corda, através da água (que foram mostrados na

\footnotetext{
${ }^{6}$ http://www.youtube.com/watch?v=TIpLyymFmgI

7 http://www.youtube.com/watch?v=04ECg1glu2s\&hd=1

8 http://www.youtube.com/watch?v=Iq3UBmSH7Ps

${ }^{9}$ vídeo filmado com o celular
} 
simulação e no vídeo) e as ondas sonoras, que são o foco principal do projeto. No caso das ondas eletromagnéticas, que, por definição, não necessitam de um meio material para se propagar (se propagam no vácuo), mas se propagam em alguns meios (transparentes), os exemplos citados foram: luz solar, luz proveniente de uma lâmpada (que são vistos diariamente pelos alunos), micro-ondas e raios-X (que são utilizados em eletrodomésticos e exames médicos).

$\mathrm{Na}$ classificação quanto à direção de vibração foram usados dois vídeos ${ }^{10} \mathrm{em}$ que eram aplicados pulsos em uma mola, em cada um deles de uma forma diferente. No primeiro, o pulso foi feito na direção perpendicular à mola, fazendo com que a mola oscilasse perpendicularmente à sua direção de repouso. Discutimos que, quando isso acontece classificamos a onda como transversal. No segundo vídeo, o pulso foi feito na direção de repouso da mola, fazendo com que a mola oscilasse nessa mesma direção. Discutimos que, quando isso acontece classificamos a onda como longitudinal. Após chegar a essa conclusão, foi comentado que as ondas sonoras se comportam dessa forma. Mas, esse comentário foi explorado com mais calma no terceiro encontro, no qual começamos a focar nas ondas sonoras, e não em ondas no geral.

\section{$2^{\circ}$ encontro (Tempo aproximado: 01:00 h; participantes: 14 )}

O segundo encontro foi iniciado com um desenho ${ }^{11}$ de uma onda se propagando em uma corda. A partir desse desenho, foram discutidos os elementos de uma onda, que são: crista, vale, amplitude, comprimento de onda, período e frequência.

Na discussão sobre os elementos de onda crista e vale, que, por definição, são, respectivamente, o ponto mais alto e o ponto mais baixo de uma onda, foram usadas analogias referentes ao surf, no caso da crista, e a lugares, no caso do vale. Quando um surfista diz que está na crista da onda, significa que ele está no ponto mais alto da onda e, um lugar é chamado de vale quando é cercado de montanhas, localizando-se no ponto mais baixo.

\footnotetext{
${ }^{10} \mathrm{http}: / /$ www.youtube.com/watch? $\mathrm{v}=04 \mathrm{ECg} 1 \mathrm{glu} 2 \mathrm{~s} \& \mathrm{hd}=1$

${ }^{11} \mathrm{http}: / / \mathrm{www}$. geocities.ws/saladefisica8/ondas/periodicas.html
} 
Na discussão sobre os elementos de onda amplitude e comprimento de onda, que são, respectivamente, a distância da posição da corda em repouso a uma crista, ou a um vale, e a distância entre duas cristas consecutivas, ou dois vales consecutivos, além de serem mostradas no desenho da corda, foi utilizada uma simulação do PhET "Onda em uma corda" na opção "Oscilador", com Amplitude 50, Amortecimento 0 e Tensão baixa, para mostrar a corda em movimento e para efetuar medições relacionadas a essas distâncias. Essa simulação contém duas réguas virtuais, uma na vertical e outra na horizontal, para efetuar medições em todas as direções, já que a simulação é bidimensional, possibilitando a medição dessas duas grandezas. As medições foram feitas pelos alunos, com auxílio do professor mediador.

Nesse momento do encontro ocorreram alguns impasses. Primeiro, a grandeza física comprimento de onda costuma ser representada pela letra grega lambda $(\lambda)$, que não tem sinal em Libras. Nesse caso foi enfatizado o conceito, evitando fazer associação com o símbolo. Segundo, os alunos não tinham concretizado na mente o significado de uma unidade de medida. Então, a discussão sobre os elementos de uma onda teve uma pausa, para que pudesse ser explicado esse significado, e serem dados exemplos, das grandezas físicas: comprimento, tempo e massa, que são as unidades bases para o estudo de Ciências, dando ênfase em tempo e comprimento, que são mais utilizadas no tema abordado. Para exemplificar algumas unidades de medida foram utilizados: no caso do comprimento, uma régua; no caso do tempo, um relógio de ponteiro; e no caso da massa, uma balança analógica, conforme a Figura 1.

Figura 1 - Print do filme realizado durante a aula 


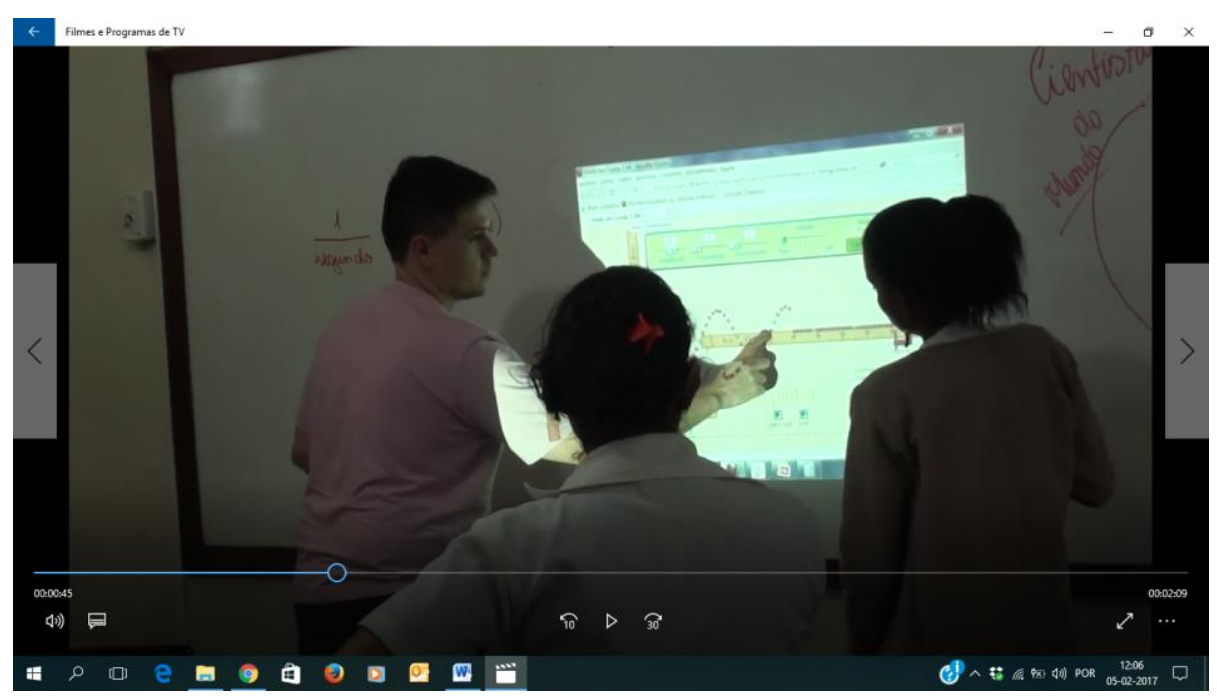

Fonte: Arquivo pessoal.

Após essa explicação sobre as unidades de medida de grandezas físicas, seguimos com o tema elementos de uma onda.

Na discussão sobre os elementos de onda período e frequência da onda, que, por definição, são, respectivamente, o tempo gasto para produzir uma oscilação completa (um ciclo), ou seja, é o tempo em que a fonte gera um ciclo de subida e um de descida (o tempo em que um comprimento de onda é percorrido), e o número de oscilações por unidade de tempo, foi utilizada uma simulação do PhET "Som", na aba "Ouvir uma única fonte". Nessa simulação pode ser ativado o áudio e alterar a frequência do som produzido pela fonte. Como os alunos não possuíam o sentido da audição, foi utilizado outro sentido, o tato. Todos os alunos puderam encostar na caixa de som, enquanto era alterada a frequência do som. Eles conseguiram perceber que, uma frequência alta fazia a caixa de som vibrar mais rápido do que em uma frequência baixa. Assim, complementando a explicação teórica com a prática.

Depois de conhecidas as grandezas físicas que compõem os elementos de uma onda, foram comentadas as suas respectivas unidades. Em sequência, através de uma regra de três, foi mostrado que as grandezas período e frequência tinham uma determinada relação. Uma é o inverso da outra.

Finalizando o encontro, foi discutido que as ondas se propagam com uma determinada velocidade, que pode ser quantificada, se tivermos conhecimento de alguns de seus elementos. Partindo da ideia de velocidade média, considerando que a 
onda vai se propagar com velocidade constante; finalmente, foram obtidas as equações conhecidas como fundamentais da ondulatória.

Considerando que o intervalo de tempo necessário para uma onda completar uma oscilação, ou percorrer um comprimento de onda, é conhecido como o período, podemos substituir o deslocamento pelo comprimento de onda sabendo que o respectivo intervalo de tempo pode ser substituído pelo período, obtendo a equação para calcular a velocidade de propagação de uma onda, dependendo do comprimento de onda e do período. Porém, também foi visto que o período é o inverso da frequência, assim, trocando essas grandezas na equação da velocidade, obtemos uma outra equação, dependendo do comprimento de onda e da frequência. Essas equações são conhecidas como equações fundamentais da ondulatória.

Para concretizar os conceitos e equações, foram utilizadas as simulações do PhET "Onda em uma corda" na opção "Oscilador", com Amplitude 50, Amortecimento 0 e Tensão baixa e "Som", na aba "Medir".

Na primeira simulação, primeiramente a frequência foi colocada em 5 e em sequência foi alternada para 10 e depois 15 . Em cada uma das três situações, um aluno fazia a medida do comprimento de onda, com a régua virtual; a medida do período da onda, com um cronômetro virtual da própria simulação, e, em sequência, calculava a velocidade de propagação da onda.

Na segunda simulação, o objetivo era calcular a velocidade do som, que propaga no ar, através das medições feitas nela. Primeiramente, a frequência foi colocada em $100 \mathrm{~Hz}$ e em sequência foi alternada para $200 \mathrm{~Hz}$ e depois $300 \mathrm{~Hz}$. Ela possui uma régua virtual, que se encontra na direção horizontal e, em cada situação, um aluno a usou para medir a distância entre duas cristas, ou vales, consecutivos, que no caso das ondas sonoras são representados por partes onde o ar está mais concentrado, ou mais rarefeito. Depois, os alunos marcavam o tempo para que esses pontos se movessem de um comprimento de onda, que é o período. Obtendo-se essas duas grandezas, pode ser calculado o valor da velocidade de propagação da onda no ar, com valores muito próximos do valor real, em torno de $340 \mathrm{~m} / \mathrm{s}$. 
$3^{\circ}$ encontro (Tempo aproximado: 01:00 h; participantes: 13)

As discussões do terceiro encontro começaram a focar no tema principal, que é: ondas sonoras. A primeira foi sobre a formação das ondas sonoras, onde foi lembrado que uma onda sonora é classificada como mecânica, pois necessita de um meio material para se propagar. Para demonstrar como isso ocorre foi utilizada uma simulação do PhET: "Ondas Sonoras", na aba "Ouvir com pressão do ar variável". Nessa, há uma caixa de som dentro de um recipiente e um boneco, representando um ouvinte. Existe também, uma opção para retirar o ar de dentro do recipiente, deixando vácuo, e assim o som para de se propagar. Como o público-alvo não era ouvinte foi priorizado outro sentido: o tato. Para que os alunos pudessem perceber que a intensidade do som diminuía com a retirada do ar, eles tocaram na caixa de som do computador, enquanto era feita a simulação. Através da vibração dela eles sabiam quando havia propagação de som.

Em sequência, foi discutido que ondas sonoras são ondas de pressão, pois se propagam através da variação de pressão do meio. Como a visão humana não é capaz de visualizar essa vibração das partículas do meio, o ar, por exemplo, quando um som é produzido, foi utilizada uma simulação que envolve um diapasão (simulação elaborada pelo Laboratório de Pesquisa e Desenvolvimento em Ensino de Matemática e Ciências da Universidade Federal do Rio de Janeiro (UFRJ)). Nessa simulação, é provocada uma perturbação no diapasão, que passa a ficar vibrando, provocando uma perturbação no ar. Nela, o ar é representado por pontos inicialmente equidistantes, simbolizando um ambiente com pressão igual em todo o espaço. Quando começam a serem produzidas as perturbações, é perceptível que esses pontos ficam se afastando, e se aproximando, representando que o ar fica rarefeito e comprimido, respectivamente. A simulação do PhET “Ondas Sonoras", na aba "Ouvir com pressão do ar variável" também ajudou na visualização das regiões rarefeitas, indicadas por arcos pretos, e na das regiões comprimidas, simbolizadas por arcos brancos. Esses arcos são intercalados. 
Um exemplo citado na explicação foi: um músico tocando um tambor. Ao tocar a membrana do tambor, ela vibra e faz com que o ar, que é o meio em que essa onda sonora vai se propagar, também vibre, fazendo com que, ora fique rarefeito (baixa pressão) e, ora fique comprimido (alta pressão), até chegar aos tímpanos dos ouvintes. Partindo do mesmo princípio utilizado na execução da simulação anterior, temos que o tato é a forma que os alunos identificam a propagação do som. Eles conseguiam perceber o som, quando estavam em contato direto, ou até mesmo, dependendo da intensidade e da frequência do som emitido, próximos a uma caixa de som. No segundo caso, a caixa de som do computador não é suficiente. Porém, nesse dia, no IEPIC tinha um evento que utilizava um amplificador que emitia um som com intensidade considerável, suficiente para eles perceberem a propagação do som, pelo ar, sem ser necessário o contato direto.

Outra classificação das ondas sonoras, que foi discutida em sequência, é que elas são longitudinais, pois a vibração das partículas do meio tem a mesma direção de propagação dele. Esse fenômeno pode ser observado com clareza na simulação do diapasão, citada anteriormente, pois o movimento que os pontos, que representam as partículas de ar, fazem é semelhante ao da mola, que foi utilizada para exemplificar uma onda longitudinal.

Foi feita referência aos elementos de uma onda, tema que foi discutido no segundo encontro, trabalhando com os alunos o conceito de comprimento de onda, voltado para ondas sonoras, que é representado pela distância entre duas regiões rarefeitas, ou duas regiões comprimidas, do meio, consecutivas. Estas são equivalentes, de um modo geral, ao vale, e à crista, de uma onda, respectivamente. Para ajudar na construção desse conceito, foi utilizada uma simulação do PhET "Ondas Sonoras", na aba "Medir", em que se pode alterar a frequência de onda e contém uma régua virtual, com objetivo de medir o comprimento de onda.

Ao finalizar o estudo de formação das ondas sonoras, retornamos a discutir o conceito de frequência de onda, mas tomando o foco para as ondas sonoras. Discutimos o fato de que o ser humano não ouve todas as frequências sonoras produzidas, apenas um determinado intervalo, que vai de aproximadamente $20 \mathrm{~Hz}$ a 
$20000 \mathrm{~Hz}$. Um ser humano não ouvirá nada quando presente em um ambiente onde se propaga um "som" com frequência fora desse intervalo. Por isso, ondas sonoras fora dessa faixa de frequência não são consideradas sons, mas infrassons e ultrassons. Os infrassons são ondas sonoras que possuem frequência abaixo de $20 \mathrm{~Hz}$, e os ultrassons, acima de $20000 \mathrm{~Hz}$.

Alguns exemplos dessas ondas sonoras foram mostrados aos alunos. Relacionado a um infrassom, foi passado um vídeo ${ }^{12}$, que já havia sido usado anteriormente, que foi o dos prédios balançando devido a um terremoto, pois os terremotos produzem infrassons. É por isso que alguns animais, que possuem sensibilidade a infrassons, podem perceber a chegada de terremotos antes dos tremores começarem. No caso dos ultrassons, apresentamos o exemplo mais comum: a foto ${ }^{13}$ de uma ultrassonografia. Assim, foi gerada uma discussão sobre os conceitos físicos aplicados nesse procedimento médico.

Um grande problema dessa discussão foram os nomes dos termos científicos infrassom e ultrassom - para os quais não haviam sinais em LIBRAS, praticamente impossibilitando a construção desse conceito. De um impasse surgiram esses dois novos sinais em Libras, que foram gravados pelos alunos do IEPIC, e serão colocados no dicionário digital de Libras ${ }^{14}$, que está sendo produzido no próprio e divulgado para o Brasil.

Em sequência, foram comentadas algumas curiosidades como: a existência de alguns animais, como o morcego, o cachorro e o gato, que possuem ouvidos sensíveis ao ultrassom. Já os elefantes e os hipopótamos, por exemplo, possuem ouvidos sensíveis ao infrassom; e que é comprovado que os tigres têm a mais forte capacidade de identificar infrassons. Seu rugido emite ondas infrassônicas tão poderosas que são capazes de paralisar suas presas e até pessoas. Para demonstrar uma delas, foi usado um vídeo ${ }^{15}$, no qual uma pessoa aperta um ursinho de pelúcia que produz barulhos ultrassônicos, ou seja, está fora da faixa de frequência que os humanos são sensíveis. Portanto, mesmo para os ouvintes, não tem som. Nesse mesmo vídeo há alguns

\footnotetext{
${ }^{12}$ http://www.youtube.com/watch?v=RmeZnW8Nc A

${ }^{13}$ http://www.uspar.com.br/setor/117473.jpg

${ }^{14} \mathrm{http}: / / \mathrm{www}$. spreadthesign.com

${ }^{15} \mathrm{http}: / / \mathrm{www}$. youtube.com/watch?v=0AKBn507mmM\&hd=1
} 
cachorros, que têm ouvidos sensíveis a ultrassons, que, enquanto a pessoa aperta o ursinho de pelúcia, ficam inquietos. Situação semelhante a que os adestradores de cães provocam ao assoprar um determinado apito, próprio para chamar a atenção desses animais.

O último conceito discutido nesse encontro foi a velocidade de propagação das ondas sonoras, que não depende da sua frequência, mas sim do meio em que ela se propaga. Se duas ondas sonoras distintas estiverem se propagando em um mesmo meio, vão possuir a mesma velocidade de propagação. Uma característica do meio que causa uma grande mudança na velocidade de propagação do som é o seu estado físico. Para mostrar aos alunos essa diferença, foram apresentadas três tabelas, uma com meios sólidos, uma com líquidos e uma com gasosos. Elas traziam as substâncias, suas respectivas temperaturas e sua velocidade de propagação. Através delas os alunos puderam perceber nitidamente que o som se propaga com maiores velocidades em meios sólidos, e com menores velocidades em meios gasosos.

Antes de finalizar o encontro, alguns alunos, que no segundo encontro não puderam trabalhar com a simulação do PhET "Som" na aba "Medir", tiveram a oportunidade de faze-lo. Foi pedido que eles calculassem a velocidade do som com diversas frequências, a fim deles perceberem que a velocidade de propagação do som não se altera com a mudança da sua frequência, mas sim com o seu comprimento de onda, o que ficou nítido no fim da manipulação dessa simulação.

\section{$4^{\circ}$ encontro (Tempo aproximado: 01:00 h; participantes: 07 )}

No quarto, e último encontro, os alunos conheceram as principais características de um som, que são: intensidade, altura e timbre.

A primeira característica discutida foi a intensidade, que está relacionada à energia de vibração da fonte que emite as ondas. Essa propriedade do som é provocada pela pressão que a onda exerce sobre o ouvido ou sobre algum instrumento medidor da intensidade sonora. Além de ser discutido o significado do conceito, foi comentada uma breve parte da história da Ciência relacionada a uma unidade de medida para essa grandeza, o decibel. A unidade de medida base é o bel, criada em 
homenagem ao cientista inglês Graham Bell (1847-1922). Contudo, utiliza-se com mais frequência, um submúltiplo dessa unidade: 1 decibel $=1 \mathrm{~dB}=0,1$ bel.

A segunda característica, discutida em sequência devido à confusão comum com a anterior, foi a altura, que nos permite classificar o som em grave ou agudo. Essa propriedade do som é caracterizada pela frequência da onda sonora. Um som com baixa frequência é dito som grave e o som com alta frequência é dito som agudo. Nesse ponto do encontro foi visto que, mesmo entre os surdos, existe o mau uso do conceito de altura de um som no cotidiano, relacionando diretamente com o volume, que é a intensidade do som. Porém, um meio que se usa corretamente esse conceito, é o meio musical. Na linguagem técnica, ou musical, dizemos que o som grave é baixo e o agudo é alto, assim sendo, concluímos que no cotidiano os termos alto e baixo, referentes à intensidade do som, são aplicados erroneamente.

A terceira, e última, característica discutida foi o timbre, que é aquela que permite distinguir sons de mesma frequência e mesma intensidade, desde que as ondas sonoras correspondentes a esses sons sejam diferentes. Pelo fato dessa característica ter uma definição mais complicada de se compreender, principalmente por alunos surdos, foi usada uma situação-problema. Esta discutia o fato de que dois instrumentos musicais, violão e violino, podem emitir sons com a mesma frequência, mas com timbres diferentes, pois as ondas sonoras possuem formas diferentes. Contudo, essa situação-problema é fundamental para a compreensão desse conceito por alunos ouvintes, mas para surdos profundos, a compreensão ainda é difícil. Durante uma mesa redonda que ocorreu no IV Eneciências em 2014 na Universidade Federal Fluminense (UFF), no Campus da Praia Vermelha, o professor de Física e pesquisador na área de pessoas com deficiências, principalmente a respeito de alunos cegos, devido ao fato de também ser deficiente visual, Eder Camargo, fez um comentário a respeito de ensinar o tema Cores, referente ao ensino de Física, mais precisamente na parte de Óptica, para alunos que nasceram cegos, ou perderam a visão muito cedo. Ele disse que é impossível fazer esses alunos, realmente, entenderem a diferença entre as cores. A partir desse comentário, se pode perceber a 
situação análoga encontrada durante a discussão do conceito de timbre com alunos que nasceram surdos, ou perderam a audição muito cedo.

O tópico final do encontro, e do projeto, foi efeitos sonoros. Foram discutidos dois efeitos sonoros causados pela reflexão do som, são eles: eco e reverberação. Contudo, inicialmente, ambos os termos não possuíam sinais em Libras, os quais foram produzidos pelos alunos ao final das discussões (Fotos 1 e 2 ) e, junto aos sinais de infrassom e ultrassom, produzidos no encontro anterior, foram gravados pelos alunos e serão adicionados ao dicionário virtual de Libras.

Foto 1 - Sinal para Eco

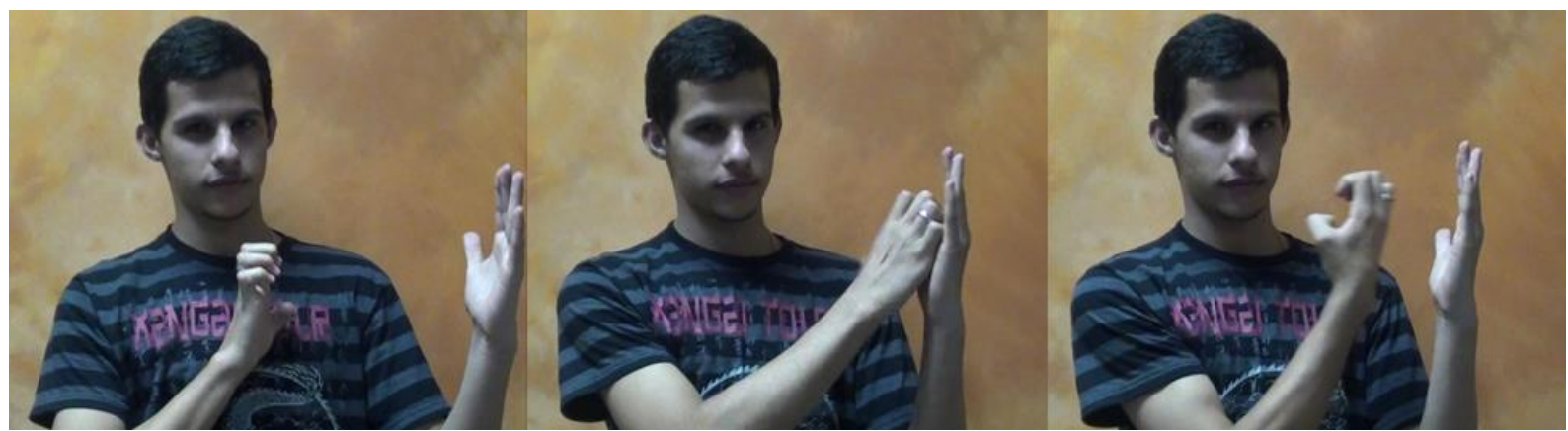

Fonte: Arquivo pessoal.

Foto 2 - Sinal para Reverberação

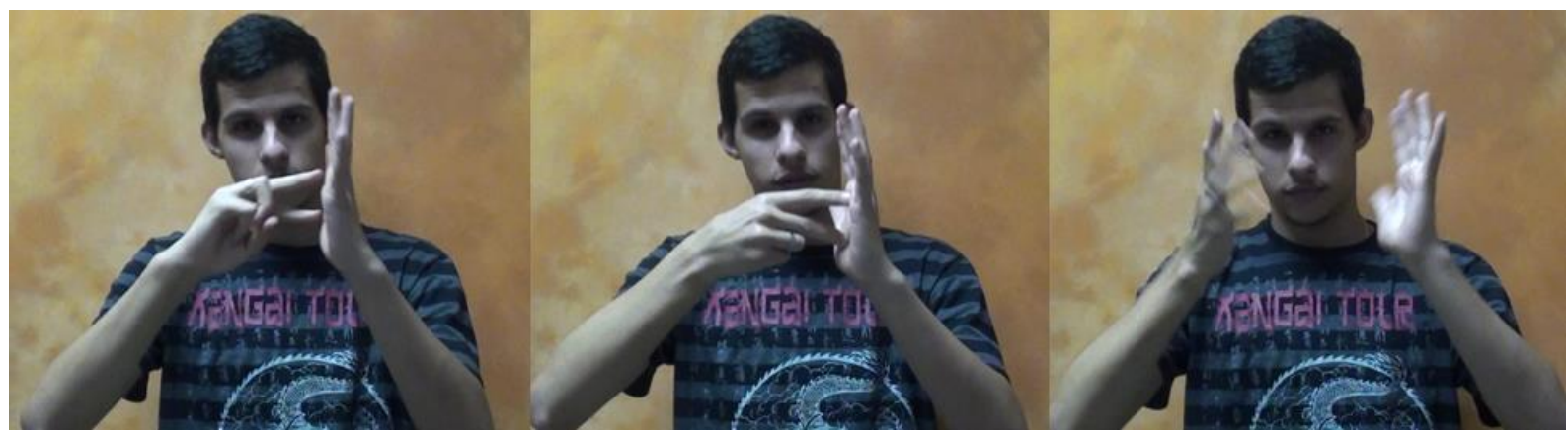

Fonte: Arquivo Pessoal.

O primeiro efeito discutido foi o eco, que é o som refletido e percebido com intervalo de tempo suficiente para ser distinguido do som original, ou seja, não há mistura do som original com o som refletido. Normalmente pode-se perceber o eco em locais onde há algum objeto muito grande e maciço, como uma parede, uma montanha ou uma caverna. Quando o intervalo de tempo não é suficiente para se distinguir o som refletido do original, ou seja, o som original se mistura com o som refletido, esse efeito sonoro é chamado de reverberação. 
Uma situação-problema utilizada para distinguir esses efeitos sonoros foi uma pessoa emitir uma palavra a 34 metros de distância de um objeto muito grande e maciço; considerando a velocidade de propagação do som no ar igual a $340 \mathrm{~m} / \mathrm{s}$, o tempo de pronúncia da palavra para que ela possa ouvi-la refletida por completo é 0,2 $s$ - os cálculos para saber esse tempo de retorno do som foram feitos com os alunos durante o encontro. Logo, para se caracterizar eco, o tempo de pronúncia da palavra deveria ser de, no máximo, 0,2 s. Logo, o som original não vai se misturar com o som refletido. Se o tempo de pronúncia de uma palavra for maior que 0,2 segundos, se caracteriza reverberação, pois o som refletido chegará antes de terminar a pronúncia da palavra. Logo, o som original vai se misturar com o som refletido.

Para ajudar na visualização da reflexão de uma onda sonora foi usada uma simulação do PhET, já utilizada em encontros anteriores, chamada "Som", mas dessa vez na aba "Interferência por reflexão". Nela é possível visualizar a onda sonora, também representada por arcos claros, representando o ar mais comprimido, e por arcos escuros, representando o ar mais rarefeito, como nas outras abas dessa simulação, mas ela possui uma barreira, que representa uma parede, onde, ao tocar na mesma, o som é refletido.

Uma curiosidade comentada com os alunos sobre esses efeitos de reflexão do som foi o fato das igrejas antigas, construídas com pedras, possuírem características sonoras marcantes. Em seu interior, o som pode se refletir várias vezes entre as paredes, produzindo um efeito de reverberação, que faz com que o som original seja acompanhado de uma sequência de sons refletidos que vão se atenuando à medida que o som é absorvido pelas paredes. Muitos concertos musicais são feitos dentro de igrejas em razão dessas características acústicas. Para confirmar o fato, foi mostrada aos alunos uma imagem ${ }^{16}$ de um concerto musical na Igreja de São Simão e São Judas, em Praga.

Depois de discutidas as definições desses efeitos foram comentadas curiosidades e aplicações práticas deles. Um exemplo é o fato do eco ser usado para medir a distância que estamos de uma montanha que produz eco: medimos o tempo

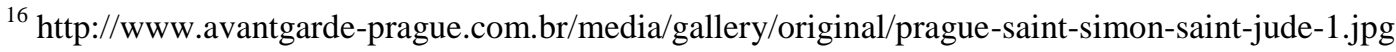


de ida e volta de um som e multiplicamos esse tempo pela velocidade do som no ar, como feito na situação-problema discutida anteriormente. A distância é a metade desse valor, pois o som precisa ir e retornar.

Outro exemplo são os sonares, mostrados em imagens ${ }^{17}$, que auxiliam embarcações e submarinos a localizar cardumes, objetos ou rochas que podem estar em seus caminhos no mar. Alguns animais possuem sonares naturais como o morcego e o golfinho, que também os usam para se localizarem no ambiente em que se encontram, mas também podem usar para comunicação com a própria espécie.

Os encontros ficaram marcados pela participação intensa dos alunos, tanto no contato direto com o professor mediador das discussões (autor dessa monografia), quanto na colaboração que os próprios alunos tiveram entre si, o que foi fundamental para a assimilação dos conceitos e situações-problema.

Os alunos fizeram muitas perguntas e sempre tentavam levar as discussões para situações que Ihes eram cotidianas, e assim, concretizar o link entre a Ciência, como forma de estudo teórico, e os fenômenos que presenciavam, ou seja, a Ciência prática. O fato deles sempre buscarem uma situação que faça esse link, em algumas situações, contribuíam para a fuga do tema central, que era Ondas Sonoras. Mas, com o auxílio do professor mediador, sempre as discussões voltavam para o tema central.

Um problema constatado no decorrer da aplicação do projeto Atividades para o ensino de ondas sonoras: uma proposta inclusiva foi que muitos intérpretes têm medo de trabalhar com determinadas disciplinas. Nesse caso, o medo de trabalhar com a disciplina Física foi visível no primeiro encontro com os intérpretes, a fim de discutir como poderíamos ensinar os conceitos desejados. Principalmente pelo fato das disciplinas de Ciências terem uma grande deficiência no vocabulário dos surdos, a LIBRAS. Isto ocasionou a saída de grande parte dos intérpretes que foram convidados a participar do projeto. Dados distintos foram obtidos por Plaça et al (s/d). Neste trabalho, a maioria dos intérpretes disse preferir as disciplinas de Ciências devido ao seu caráter visual, que facilita o entendimento dos conceitos pelo fato da comunicação dos surdos ser estritamente visual. Estes relatam que a dificuldade em interpretar

\footnotetext{
${ }^{17}$ http://images.yourdictionary.com/sonar

http://askabiologist.asu.edu/echolocation
} 
aulas de disciplinas inclusas nas Ciências Humanas é que estas possuem caráter de conversação, sendo quase todas baseadas em comunicação não visual. Sendo que estas também possuem termos como "Rei Fulano de Tal", que não têm sinais em Libras.

A participação da intérprete presente na SRM do IEPIC também foi de suma importância. Além de ser o link entre o professor mediador e os alunos, ela participou das discussões. Tentava compreender as informações que estavam sendo transmitidas para eles e, muitas vezes, quando os alunos não compreendiam, ela primeiramente explicava o jeito que tinha compreendido, e, quando estava correto, tentava passar para os alunos, com uma linguagem mais coloquial, em Libras.

Outras dificuldades foram percebidas nos encontros. E uma delas é comum, não só para alunos com deficiência auditiva ou surdos, mas também pode ser percebida em salas de aula consideradas convencionais, que é a dificuldade dos alunos manterem a atenção durante todo o período de aula. Outra, com um grau de dificuldade mais elevado é o fato do vocabulário, principalmente o científico, em Libras, ser bastante deficiente. Em vários momentos a aula teve que ser interrompida para explicar termos, ou até mesmo criar novos sinais para esses, relacionados ao tema, para tornar possível o prosseguimento da aula. Um exemplo disso foi o termo científico comprimento de onda, normalmente representado pela letra grega $\lambda$, que não possui sinal em Libras. Nesse caso visamos à associação do conceito físico naquele símbolo $(\lambda)$. Um exemplo distinto foi o caso dos termos: infrassom, ultrassom, reverberação e eco. Nesse caso, os alunos, após a discussão dos significados de cada termo, criaram sinais em Libras para esses, que pouco tempo depois foram adicionados ao dicionário digital em Libras que está sendo produzido, junto aos alunos do IEPIC, em sua SRM.

No decorrer dos encontros, ficou nítida a dificuldade de se trabalhar o tema escolhido devido a diversos fatores. Alguns destes já eram esperados por já terem sido indicados em algumas referências bibliográficas e a experiências anteriores. Porém, outros que não eram esperados apareceram, pois não eram específicos do público surdo, logo não eram comentados em referências bibliográficas. 
Os que eram esperados, dizem respeito à defasagem da língua usada pelos surdos, a Libras, principalmente quando se trata do vocabulário científico. Uma estratégia aplicada para tentar superar essas barreiras foi criar sinais para termos que são importantes para a compreensão do conteúdo abordado, quaisquer que fossem eles, e para termos que são usados com frequência em frases do meio científico. Nesse segundo caso foi possível também adaptar o termo sem sinal em Libras para um vocabulário mais coloquial, que possuísse sinais em Libras. Porém, para ser feita essa adaptação, serão necessários encontros prévios do professor com os intérpretes que não dominam os conteúdos científicos.

Antes da aplicação do projeto, essa estratégia foi pensada e colocada em prática, mas não surtiu tanto efeito devido ao medo dos intérpretes convidados, inicialmente, para participar, pois perceberam que muitos termos não tinham sinais ou eles não conheciam por não terem costume de usar. Além disso, alguns termos que possuíam sinais em Libras tinham um significado diferente do científico. Como exemplos, temos: massa, que está reacionado à massa de modelar e não ao conceito físico, que trata da dificuldade de tirar um corpo do seu estado inercial; e onda, que está relacionada à onda no mar e não à propagação de uma perturbação realizada sobre determinado meio.

Vendo as dificuldades, estes intérpretes desistiram de participar do projeto, e teve de ser convidada uma intérprete de fora da escola. Por isso a estratégia não ajudou tanto, mas fez com que o vocabulário dos encontros fosse voltado para o coloquial, sempre que possível, esperando que houvesse sinais suficientes para um diálogo natural para os surdos. Porém, os termos científicos envolvidos não podiam ser trocados, logo tiveram que ser criados sinais para um melhor andamento dos encontros. Contudo, isso não é simples. Primeiramente, para um sinal entrar na língua dos surdos, estes devem aceitá-lo. A estratégia utilizada foi a criação destes pelos próprios surdos, após a explicação de seus significados. Segundo, mesmo depois de criado o sinal, e este sendo aceito pelo público que o utilizará, precisa-se de tempo e hábito de uso. Senão o sinal cai no esquecimento rapidamente. Como exemplo visto em um dos encontros, o termo internacional, que já possuía um sinal em LIBRAS e 
havia sido discutido com os alunos que participaram do projeto, em situações anteriores com outros professores, havia caído no esquecimento. Este fato foi avistado quando foram discutidas as unidades de medida, onde usamos o termo Sistema Internacional de Unidades, e eles não identificaram significado no sinal da palavra internacional.

Outra dificuldade encontrada, e que não era esperada, também apareceu no mesmo tópico, unidades de medida. Os alunos que estavam presentes não compreendiam o significado das unidades de medida de uma grandeza física. Eles sabiam o que era tempo, mas não sabiam a diferença de hora, minuto e segundo. A mesma ideia se propagava para as unidades de medida de comprimento. Neste momento ocorreu uma intervenção da professora da SRM, que rapidamente identificou a dificuldade dos alunos, e auxiliou na explicação desses conceitos, possibilitando a sequência do encontro.

Durante grande parte do projeto ocorreu o surgimento de dificuldades comuns, já expostas por outros autores, e algumas que não tinham sido, mas o projeto não se resumiu a encontros com dificuldades. Fator importante para a compreensão de alguns conceitos, que, mesmo com toda paciência, a intérprete, que muitas vezes compreendia o que estava sendo discutido e adaptava de uma forma mais fácil para o público-alvo, não conseguia fazer todos entenderem; um aluno que havia compreendido, explicava aos outros de uma nova forma. Depois, a intérprete traduzia o que este aluno passou, para confirmar se realmente estava correto. Essa colaboração dos alunos com o professor mediador, e com os outros alunos, ajudou muito no desenvolvimento dos encontros. Esse foi um grande momento do projeto. O encontro com uma situação que deve ser mais bem explorada pelos educandos. Logo, quando se consegue atingir um determinado grupo de alunos, mesmo sendo um número restrito, seja pela dificuldade de explicar algum fenômeno ou, simplesmente, por dificuldades na língua (Ex: Falta de sinais compatíveis com o tema abordado), aqueles que compreenderam vão ajudar aos outros. O ensino colaborativo (GILLIES; BOYLE, 2010) é fundamental para o processo de ensino-aprendizagem, não só de alunos com deficiência, mas para o processo de ensino aprendizagem de qualquer aluno. 


\section{CONSIDERAÇÕES FINAIS}

Independente do público-alvo com que o professor venha a se confrontar, este deve estar sempre com a mente aberta para adaptação na sua aula, seja previamente, ou durante ela. No caso da aplicação desse projeto, ao longo da preparação do projeto-aula, os tópicos a serem abordados foram sempre pensados visando as possíveis dificuldades a serem deparadas durante o processo de ensino-aprendizagem. Esse planejamento e reflexão prévios são fundamentais para prevenir situações complicadas, mas mesmo assim, dificilmente uma aula, mesmo que planejada, sai totalmente de acordo com o que se esperava. Uma aula não é um objeto sólido. Ela necessita de intervenções e adaptações antes, durante e, em alguns casos em que não se alcançou o desejado, depois.

Durante esses encontros ocorreram diversas situações inesperadas, quando a aula precisou ser readaptada por acontecer uma situação que não foi prevista. 0 exemplo mais forte foi o das unidades de medida. Não tinha sido imaginado que aqueles alunos não lembravam, ou não sabiam, quais são as unidades de medida de tempo e comprimento, por serem bastante usuais. Neste momento o planejamento mudou. Nem todos os tópicos que seriam apresentados no encontro, foram trabalhados. A intervenção foi feita pela professora da SRM, naquele momento, uma maneira de trabalhar essas unidades de medida, como foi descrito anteriormente.

Essa intervenção não foi prevista pelo fato de que quando foi elaborado o projeto-aula, o que se sabia do público alvo, eram informações generalizadas, e não focalizadas naquele grupo. Coisa que um professor que ministra uma turma durante todo um ano letivo ou mais, pode prever, simplesmente conhecendo seus alunos. Mesmo sendo algo que não era esperado, foi bem trabalhado, e o objetivo foi alcançado, podendo assim prosseguir o planejamento.

Além de o professor elaborar o projeto-aula buscando sempre adaptar a aula para o público-alvo, este deve discuti-lo com o intérprete que irá ajudá-lo, pois ele é o principal pilar da comunicação entre professor e aluno, no caso dos alunos surdos. 0 intérprete deve contribuir com sua opinião, principalmente no que se trata da 
linguagem a ser usada.

O intérprete é fundamental para o desenvolvimento de uma aula com alunos surdos, mas ele não deve ficar limitado a simplesmente traduzir a informação dita pelo professor da disciplina a ser trabalhada. Este deve ter comprometimento com a aula em si, fazendo o possível para compreender o que o professor da disciplina vai apresentar, pois a LIBRAS é limitada, principalmente quando se trata da linguagem científica. Se o intérprete compreender o assunto, em um caso onde haja dúvida dos alunos, e que o professor da disciplina não consiga mais adaptar suas palavras para facilitar a tradução, este pode conseguir, pois possui uma noção muito maior de palavras que podem ser substituídas em Libras, e que podem facilitar a compreensão dos alunos.

Mas um ponto crucial de se desenvolver uma aula, independente da disciplina, do tema, ou do público-alvo, é assegurar que haja interação, não só entre o aluno e o professor, mas também entre os alunos como um todo. Esse fator pode possibilitar uma melhor compreensão de determinados conceitos para alguns alunos que tiveram dificuldade com a linguagem utilizada em certos instantes, e que nem o intérprete consiga esclarecer de forma efetiva o que foi comunicado, como, em um caso análogo, onde possa se usar uma linguagem muito científica com alunos do ensino fundamental, que não estão adequados a ela, logo terão dificuldade de compreender. No caso dos alunos surdos ainda é mais importante, pois além de terem que enfrentar a barreira da dificuldade do conteúdo, comum a todos os públicos, estes encaram uma outra, a da língua. Sendo assim, se pelo menos um dos alunos compreender o assunto discutido, este deve ser usado de ponte, além do intérprete, para atingir os outros, pois para ele fica muito mais fácil adaptar a linguagem de uma forma mais coloquial, devido à sua vivência e ao contato cotidiano com a sua turma.

Essa interação entre todos os indivíduos que compõem o processo de ensinoaprendizagem pode possibilitar a inclusão no meio escolar, e, possivelmente, fora dele, pois, tanto os alunos surdos quanto os ouvintes, devem interagir na sala de aula, se for o caso de uma turma mista, e fatalmente carregam esse contato para fora do meio escolar. Isso pode gerar a quebra de um preconceito tido por outros indivíduos que 
não têm contato com surdos, simplesmente por não falarem a mesma língua.

O grupo que participou do projeto foi aos poucos se entrosando com o licenciando regente das atividades sobre ondas sonoras e as intervenções extras foram reduzidas. Pela observação direta durante os encontros, foi possível perceber que os alunos compreenderam os conceitos fundamentais, através das associações de ideias que eles fizeram entre os conceitos físicos abordados e as situações do cotidiano deles. Sendo assim, conclui-se que houve um saldo positivo de aprendizagem no grupo. Uma associação que havia sido planejada, mas não da forma como foi feita, foi em um dia que havia um evento no IEPIC para o qual estava sendo usado no pátio um amplificador muito potente e os alunos tinham passado perto dele. Durante o nosso encontro desse dia seria utilizado um amplificador menor na SRM, emitindo um determinado som. Os alunos deveriam se aproximar e seriam questionados se podiam sentir que existia um som sendo emitido sem tocarem na caixa. Como eles já haviam passado por um amplificar ligado, o fato foi aproveitado e apenas foi feito o questionamento. Eles disseram que sim. Com isso pode ser concluída a ideia de que o som é uma onda mecânica, logo necessita de um meio material para se propagar, nesse caso o ar, e causa perturbação nele. Fato sentido pelo tato ao se aproximar do amplificador do pátio.

Inclusão se faz com ganhos de aprendizagens substantivas, com circulação e acesso à escola; com valores e sentido de pertencimento. $\mathrm{O}$ entendimento é de que o aluno não aprende apenas na sala de aula, mas na escola como um todo. Faz-se necessário que a escola seja, em seu conjunto, um espaço favorável à aprendizagem e à equidade, e o IEPIC hoje caminha para garantir essas condições.

A Inclusão beneficia a todos, uma vez que todos podem desenvolver sentimentos de respeito à diferença, de cooperação e de solidariedade. Um ideal que pressupõe um mundo diferente desse nosso, em que a agressividade e a competitividade não sejam tão avassaladoras, um mundo no qual a cooperação não tenha como pressuposto moral a piedade, geradora de benemerência.

Essa proposta de aula não é garantia de sucesso. É necessário que para cada grupo o professor tenha um olhar crítico para que possa fazer analogias mais próximas 
do cotidiano do grupo com quem está trabalhando, sempre tentar se adequar aos alunos, e não fazer com que eles tentem se adequar ao professor, sempre buscar novas formas de se apresentar um novo conteúdo sempre aproveitando o que esse grupo tem de melhor, como no caso dessa proposta, aproveitando o contato físico, o tato. Para isso, o professor deve sempre tentar conhecer ao máximo a sua turma, pois senão este fica impossibilitado de se preparar previamente para trabalhar qualquer conteúdo. Esta proposta não ficará limitada a esse trabalho, pois como dito anteriormente, para cada público se deve trabalhar de uma forma diferente. Logo, estudando o máximo de grupos distintos, se pode avaliar melhor os pontos positivos e negativos, e elaborar novos métodos, de acordo com as novas barreiras encontradas, que podem ser particulares de determinado grupo, mas se superadas para este, podem ser mais esclarecedoras para os outros. 


\section{Referências}

BRASIL. Constituição da República Federativa do Brasil de 1988.

Lei № 7.853, de 24 de outubro de 1989. Dispõe sobre o apoio às pessoas portadoras com deficiência. Diário Oficial da União, Brasília, DF, 25 outubro 1989.

MEC. Política Nacional de Educação Especial na Perspectiva da Educação Inclusiva. Documento elaborado pelo Grupo de Trabalho nomeado pela Portaria Ministerial $n$ ㅇ 555, de 5 de junho de 2007, prorrogada pela Portaria № 948, de 09 de outubro de 2007. Inclusão: R. Educ. esp., Brasília, v. 4, n. 1, p. 7-17, jan./jun. 2008. Disponível em: http://portal.mec.gov.br/seesp/arquivos/pdf/revinclusao5.pdf. Acesso em: 10 junho 2014.

MEC. Ministério da Educação. Secretaria de Educação Especial-SEESP. ARANHA, Maria Salete Fábio (Org.). Estratégias para a educação de alunos com necessidades educacionais especiais. Brasília: MEC/SEESP, 2003. Disponível em: http://portal.mec.gov.br/seesp/arquivos/pdf/serie4.pdf. Acesso em: 14 abril 2014.

Política nacional de educação especial na perspectiva da educação inclusiva. Inclusão: Revista da Educação Especial, Brasília: MEC, 4(1): 7-17, 2008.

CARVALHO, Anna Maria Pessoa de. Pesquisas em sala de aula: um importante fator na formação do professor. Revista Perspectiva, Florianópolis: Perspectiva, v. 10, n. 17, p. 47-57, $1992 . \quad$ Disponível em: https://periodicos.ufsc.br/index.php/perspectiva/article/download/9148/10690. Acesso em: 22 maio 2013.

CONFERÊNCIA MUNDIAL SOBRE NECESSIDADES EDUCATIVAS ESPECIAIS: ACESSO E QUALIDADE, 7, 1994, Salamanca, Espanha. Declaração... Paris: UNESCO, 1994.

ESTADO DO RIO DE JANEIRO. Secretaria de Estado de Educação. Currículo Mínimo RJ2012. Física. Disponível em: http://www.rj.gov.br/c/document_library/get_file?uuid=7fa099a8-14b5-46f4-ad934b9a5c5f9bd2\&groupld=91317. Acesso em: 28 março 2014.

GILLIES, Robyn M.; BOYLE, Michael. Teachers' reflections on cooperative learning: 
Issues of implementation. Teaching and Teacher Education. 26, p. 933-940, 2010.

GOLDFELD, M. A criança surda: linguagem, cognição, numa perspectiva interacionista. São Paulo: Plexus, 2002.

MARIANI, R. Libras - A Construção e a Divulgação dos Conceitos Científicos Sobre O Ensino de Ciências e Biotecnologia: Integração Internacional de um Dicionário Científico Online. Tese de doutorado (Pós-graduação em Ciências e Biotecnologia), Instituto de Biologia, Universidade Federal Fluminense, 2014. p. 5-263.

MARINHO, Margareth Latt. O ensino da Biologia o intérprete e a geração de sinais. Disertação de Mestrado da Pós- Graduação em Linguística da UNB, Brasília, 2007.

NASCIMENTO NETO, Moacir Cardoso do. O ensino de acústica para alunos surdos e ouvintes a partir dos livros didáticos. VI Colóquio Internacional "Educação $e$ Contemporaneidade”. São Cristovão, SE, 2012.

NOGUEIRA, Lívia S.; REIS, Liliane R.; RICARDO, Elio Carlos. Ensino de Física para portadores de deficiência auditiva: o problema dos livros didáticos. XVI Simpósio Nacional de Ensino de Física, Rio de Janeiro, CEFET, 2005.

PLAÇA, Luiz Felipe; GOBARA, Shirley Takeco; DELBEN, Angela Antonia Sanches Tardivo; VARGAS, Jaqueline Santos. As dificuldades para o ensino de Física aos alunos surdos em escolas estaduais de Campo Grande-MS. Campo Grande, MS: UFMS\CCET, s/d.

RUMJANEK, V. O uso do conhecimento científico como forma de incluir o surdo na sociedade. Acessado em http://www.faperj.br/boletim_interna. phtml? obj_id=4877, 2008.

SILVA, Márcia Garcês. A inclusão do aluno surdo no ensino regular. Piauí: UESPI, 2010.

\section{SITES UTILIZADOS}

http://www.youtube.com/watch?v= 14HYrtMI7U\&hd=1

http://www.youtube.com/watch?v=RmeZnW8Nc A

http://www.youtube.com/watch?v=y2yFHhfOVJM\&hd=1

http://phet.colorado.edu

http://www.youtube.com/watch?v=04ECg1glu2s\&hd=1 
http://www.geocities.ws/saladefisica8/ondas/periodicas.html

http://www.youtube.com/watch?v=04ECg1glu2s\&hd=1

http://www.youtube.com/watch?v=TfVy7wbwEyE\&hd=1

http://www.youtube.com/watch?v=TIpLyymFmgl

http://www.youtube.com/watch?v=04ECg1glu2s\&hd=1

http://www.youtube.com/watch?v=lq3UBmSH7Ps

http://www.youtube.com/watch?v=04ECg1glu2s\&hd=1

http://www.geocities.ws/saladefisica8/ondas/periodicas.html

http://www.youtube.com/watch?v=RmeZnW8Nc A

http://www.uspar.com.br/setor/117473.jpg

http://www.spreadthesign.com

http://www.youtube.com/watch?v=0AKBn507mmM\&hd=1

http://www.avantgarde-prague.com.br/media/gallery/original/prague-saint-simon-saint-jude-1.jpg http://images.yourdictionary.com/sonar

http://askabiologist.asu.edu/echolocation 